The Geneva Papers on Risk and Insurance, 16 (No. 60, July 1991), 293-301

\title{
Some Considerations on Productivity and Performance in Insurance
}

\author{
Preliminary findings of a study of the Italian insurance industry
}

by Antonio Borghesi *

\section{Nature and object of this discussion}

The discussion which follows sets out to illustrate the preliminary findings of a study recently undertaken by the Institute of Industrial, Banking and Service Sector Studies of the University of Verona. This research, which is partly financed by the Ministry of Universities, aims to consider all problems relative to the selection and choice of an insurer.

The object of the study would not have held much interest in the past when the Italian insurance market was for the most part protected.' Together with the many disadvantages such a protected market had for the would-be policy holder (oligopoly, the formation of price cartels, premiums being adapted to the least efficient operators, etc.), there was nevertheless the advantage that the idea of an insurance company's going out of business was purely hypothetical and need not for all practical purposes be taken into account. In fact, when an insurance company was no longer in a position to meet its commitments, the system intervened with some form of rescue operation which eliminated or limited the negative consequences for the policy holders via a disguised form of loss sharing.

Over recent ycars, however, and particularly as a result of the application of EEC directives aimed at standardizing the legislation of member states, there has been a continual move back to competition in the Italian insurance market. Deregulation of the sector will be fully implemented in time for the introduction of the Singlc European Market at the beginning of 1993 and there is good reason to believe that from that date on choosing an insurance company will once again, like the choicc of any othcr service, bccome a matter requiring caution. This will be especially truc for companics seeking insurance.?

\footnotetext{
* Full Professor of Business Finance at the University of Calabria, Italy and Professor of Marketing at the University of Verona, Italy. Text presented at the Workshop on Productivity and Performance in Insurance, Paris, January 1990.

${ }^{1}$ This would seem to be an almost obligatory stage for all European countries, including Great Britain. Cfr. Ratcliff A. R. N. (1983), p. 237.

2 Borghesi, A. (1985), p. 280.
} 
A selection process such as to guarantee a properly considered choice of insurer must, in our opinion, involve an assessment of at least three parameters: ${ }^{3}$

1. economic/financial and asset-related reliability;

2. level of service;

3. cost.

It is within this frame of reference that it becomes important to study the performance of insurance companies.

Such a study involves the measurement of a wide range of parameters, including:

1. the efficiency with which each insurance company employs the incomes it receives;

2. the level of service offered, its quality, image, and most importantly the extent to which it satisfies the needs of the consumer;

3. the sales rate, by which we mean the yearly increase in earned premiums.

\section{Some problems of definition}

We feel a brief discussion of what we mean when we use certain commonly recurring terminology would be useful.

By efficiency we mean a generic measure of performance, defined by the relationship between the results achieved and the range (in quality, quantity and value) of means employed; or we could say the relationship between the input and output of a given productive unit or of a subsystem or productive phase of that unit. ${ }^{4}$

If both the results achieved and the means employed are expressed in terms of physical quantities the result will offer an index of technical efficiency or productivity.

If, on the other hand, the terms of the relationship are expressed in monetary quantities, the result will give an index of economic efficiency or, as we put it, economicy.

The extent to which an organization achieves its own goals and predetermined objectives we refer to as the company's effectiveness.

It goes without saying that any assessment of the performance of an organization must take into account both efficiency and effectiveness, the former offering a measurement of the situation within the company and the second a measurement of its relationship with the world around it. ${ }^{5}$

The notion of productivity may take on different meanings depending on whether we are talking about the distinct elements of production or production as a whole. ${ }^{6}$ The two concepts are differentiated by using the terms, specific or partial productivity and total or global productivity.

${ }^{3}$ There is general agreement in the literature here, though with some difference in emphasis. Cfr. Greene M. R. - Trieschmann G. S. (1981) p. 110 and following; Williams C. A. - Heins R. M. (1976), p. 439 and following; Greene M. R. - Serbein D.S. (1981), p. 351 and following; Pfeffer I. - Klock D. R. (1974), p. 458 and following.

+ Panati G. (1973), p. 27.

s Baccarani C. (1987), p. 91.

${ }^{6}$ Fourastiè J. (1959), p. 51 and following. 
Productivity indices offer objective criteria for a rationalization of operations since they allow for research into the possiblc maximization of physical results achieved with respect to the means employed. As has rightly becn pointed out, however, an improvement in productivity is a necessary, but not a sufficient condition for improvement in a company's economicy. ${ }^{7}$

Moving from the concept of productivity to that of cconomicy implies giving economic values to the terms of the ratio used to calculate productivity. The concept of economicy thus corresponds to a study of ways of minimizing the monetary cost necessary for returning a given result. Measurement of economicy allows us to verify the lcvcl of productivity, since an improvement of the latter may have been achieved with a higher than proportional increase in relevant costs. When looking at the parameters that make up economicy, particular attention should be given to profitability, which cxpresses the ratio of profit to owned capital or total capital invested.

Profitability gives us at once:

1. an indication as to whether the company would be a good investment;

2. an indication of an objective to be achicved.

Comparisons of a company's economicy at different moments in time (an important method for determining whether performance is improving or deteriorating) require that the relationships involved:

1. are calculated with price levels kept constant;

2. are considered in relation to any variation in the composition of inputs and outputs. ${ }^{8}$

Finally, it is worth remembering that an overall consideration of efficiency indices, that is a calculation of the efficiency of a whole industrial sector, will allow us to make comparisons between individual companies in the sector and to establish their relative positions. This presupposes, however, that the companies under consideration produce the same product or offer the same service, and even when this is the case there remains the question of differences in quality due to different technologies or other factors. ${ }^{9}$

\section{Effectiveness, efficiency, productivity, economicy and profitability in insurance companies}

We could hardly not agree with Carter's reflections on the problems involved in calculating the performance and efficiency of insurance companics, ${ }^{10}$ in particular with reference to:

- the conceptual and practical problems that have to be overcome if onc is to measure performancc;

- the fact that the reading and interpretion of any cfficiency index requires special caution in the absence of which onc might arrive at mistaken conclusions;

- the difficultics of dcfining the product or servicc of the insurance company;

\footnotetext{
7 Panati G. - Golinelli G. (1989), p. 105.

s Lawlor A. (1985), pp. 42-46.

${ }^{9}$ Kendrick J. W. (1985), p. 114.

${ }^{10}$ Carter R. L. (1979), p. 175 and following.
} 
- the problems involved in calculating profitability as a result of difficulty in establishing what is the numerator (the profit) and what is the denominator (the capital invested). For an appreciation of the problems on the profit side, one need only consider the duration of insurance contracts, particularly in the arca of life insurance, and the question of whether or not to take into account capital gains and losses; as far as the capital is concerned there is the problem of whether or not to include the tcchnical reserves, which would make comparisons with other scctors impracticable.

However, despite all the various problems of interpretation, theory and practice, it is our opinion that the parameters used for assessing the performancc and efficiency of businesses in other scctors, and in particular the manufacturing sector, should be considered. After all, the banking sector poses analogous problems, yet still applies the same parameters."

What we do feel should be stressed is that while some indices are neither more nor less than those applied to any business activity (eg. those which refer to labour), others take on precise connotations as a result of the peculiar nature of the insurance business and should always be calculatcd for cach singlc branch of a company's activitics.

So, to give an example, identification of the level of effectiveness, while acknowledging that this depends to a large extent on quality-related factors, can nevertheless be calculated by resorting to a series of quantitative indicators, from which one can then draw valuable conclusions on the quality of the company's performance. In the area of insurance, without in any sense pretending to be exhaustive, examples of such quantitative indicators could include ${ }^{12}$ the number of claims paid in a year in relation to the number of claims made; the average time taken to pay claims; the number of new insurance products put on the market each year; the number of legal cases begun each year in relation to the number of claims made; the interest rate offered to life-insurance policy holders; the number of complaints presented to the surveillance body, and so on. ${ }^{13}$

Likewise, indicators of productivity could be: the number of policies per employee; the value insured per employee, value of premiums paid per employec, etc.

Indicators of economicy could include: the claims ratio (ratio of incurred losses to earned premiums); the purchasing expenses ratio (ratio of expenses for purchasing and production to earned premiums); the management expenses ratio (ratio of general administrative expenses to earned premiums), the expenses ratio (ratio of global expenses for both purchasing and management to earned premiums), and finally the combined or trade ratio, that is the sum of the claims ratio and the cxpenses ratio.

Finally, profitability indicators could be taken to include: the ratio of charges on assets and loans to income from assets and loans; the ratio of the costs of technical management (by which we mcan insurance management in the strictest sense) to the income procceding from it ; the ratio of earnings from management of real estate to money invested in real estate; the ratio of the profit or loss ensuing from technical management to earned premiums; and the ratio of yearly profit or loss to owned capital.

\footnotetext{
11 Gregermann I. B. (1987), p. 338 and following.

12 Borghesi A. (1988), p. 32.

13 Pfeffer I. - Klock D. R. (1974), p. 408.
} 


\section{Problems involved in measuring the performance of Italian insurance companies}

Onc of the major problems onc usually faces when trying to assess the performance of insurance companies is the lack of data available. ${ }^{14}$

This is particularly truc in Italy where only after the law by which the country adopted the EEC Dircctivc on damage insurance, did insurance companies begin to formulatc unified and obligatory balance sheets and income statements in suh a way as to allow for analysis. ${ }^{15}$

Even now, the situation secms designed morc to aid the work of the surveillance body, presently known as ISVAP (Institute for the Surveillance of Private Insurance Arrangements) than to give clear information to everybody about the way insurance companics are managed. So much so that ccrtain analyses, including calculation of the solvency margin, are only possible if one can get hold of data that the companies are obliged to send to the surveillance body.

In this regard, we feel it would be worth proposing two alternative measures to be undertaken at European level.

The first consists either in introducing a unified method of balance sheet and income statement presentation for all European insurance companies, or at least obliging companies to publish such information as would make accurate calculation of the above-mentioned indices possible.

The alternative would be to try to get companies to provide such information voluntarily through the creation of an independent body capable of offering an information service giving details of reliability parameters and levels of service in the companies in the sector. Such a body ${ }^{16}$ would certainly be justifiable, given the size of the European Insurance market as a whole, and could produce an annual classification of companies, obliging them, if they are not to be left out of the classification, to provide the information which at present they keep secret.

\section{Preliminary findings of our study of the performance and efficiency of insurance companies operating on the Italian market}

Despite the difficulties and limitations already discussed, we are nevertheless attempting to calculate some of the indices described above using what data is in the public domain.

During this first phase of our research we have restricted the study to the indices of cconomicy and profitability, since they are simpler to calculate than the others, in that they can be deduced from companies' annual balance sheets and income statements.

In particular, we considered the following indicators:

14 Regarding which, Carter R. L. (1979), p. 177, points out that although a certain amount of progress has been made, the analysis of Lengyel S. J. (1947) still holds good thirty years after it was written.

is Ceriani G. (1984), p. 217.

16 For example, in the USA the Best Insurance Report has been available for many years now. Considering 11 balance sheet and income statement indices the Report gives its assessments of the insurance companies, assessments which are given serious consideration by policy holders. 

A) The claims ratio $=$ incurred losses/earned premiums
B) The purchase expenses ratio = expenses for purchases, production and organization/ earned premiums
C) The management expenses ratio = general administration expenses/earned premiums
D) The total expenses ratio $=$ purchasing expenses + administrative expenses/earned premiums
E) The combined or trade ratio = claims ratio + the total expenses ratio
F) Charges of assets and loans/earnings from assets and loans
G) Costs of technical (typical) management/earnings from technical management
H) Earnings from management of real estate/investment in real estate
I) Profit or loss ensuing from technical (typical) management/earned premiums
L) Operating profit or loss/capital owned.

Our findings are shown in Tables 1 and 2. Table 1 shows overal results for all companies operating in the damage insurance market in Italy, while Table 2 shows results for all companies operating in the life insurance market in Italy. The data refers to balance sheets of 1986.

For each index we have calculated the mean, the standard deviation, the coefficient of variation, maximum and minimum values, asymetry and kurtosis.

\section{Table 1}

Indices of efficiency and profitability of companies operating in damage insurance in Italy in 1986 (in percentages)

\begin{tabular}{lrrrrrrr}
\hline INDEX & \multicolumn{1}{c}{ M } & S.D. & C.Var. & Min.Val & Max.Val & As & Kur \\
\hline A & 79.68 & 54.41 & 68.29 & -50.00 & 700.00 & 8.06 & 95.38 \\
B & 21.00 & 23.61 & 112.42 & -60.00 & 175.00 & 2.99 & 18.77 \\
C & 10.99 & 152.03 & 1382.77 & 00.00 & 1300.00 & 6.85 & 51.89 \\
D & 32.00 & 150.72 & 471.03 & 00.00 & 1300.00 & 6.43 & 46.94 \\
E & 111.68 & 157.89 & 141.38 & -50.00 & 1400.00 & 6.08 & 41.96 \\
F & 6.28 & 25.50 & 405.87 & 00.00 & 207.14 & 5.40 & 36.61 \\
G & 99.93 & 9.68 & 9.68 & 30.00 & 118.18 & -4.17 & 24.26 \\
H & 7.25 & 7.53 & 103.84 & 00.00 & 63.64 & 3.14 & 23.13 \\
I & 0.26 & 34.04 & 12972.18 & -135.71 & 150.00 & 0.66 & 7.64 \\
L & 8.37 & 170.75 & 2039.29 & -916.67 & 1950.00 & 7.08 & 96.84 \\
& & & & & & & \\
\hline
\end{tabular}


Table 2

Indices of efficiency and profitability of companies operating in life insurance in Italy in 1986 (in percentages)

\begin{tabular}{lrrrrrrr}
\hline INDEX & \multicolumn{1}{c}{ M } & \multicolumn{1}{c}{ S.D. } & C.Var. & Min.Val & Max.Val & \multicolumn{1}{c}{ As } & Kur \\
\hline A & 129.27 & 96.29 & 74.49 & -195.83 & 426.73 & -0.89 & 5.34 \\
B & 111.88 & 922.17 & 824.25 & -6800.00 & 934.62 & -7.25 & 54.42 \\
C & 36.21 & 461.41 & 1274.20 & -2900.00 & 1600.00 & -3.81 & 30.65 \\
D & 148.09 & 1116.64 & 754.01 & -7333.33 & 2050.00 & -5.48 & 35.99 \\
E & 277.36 & 1156.75 & 417.05 & -7529.17 & 2050.00 & -5.54 & 36.37 \\
F & 10.91 & 15.26 & 139.82 & 00.00 & 68.89 & 2.32 & 8.60 \\
G & 105.62 & 7.03 & 6.65 & 80.09 & 133.22 & 0.00 & 8.01 \\
H & 12.60 & 6.97 & 55.29 & 00.00 & 24.66 & -0.95 & 2.09 \\
I & -142.76 & 972.56 & -681.23 & -961.54 & 7095.83 & 7.10 & 52.92 \\
L & 13.58 & 95.88 & 706.09 & -26.00 & 740.63 & 7.39 & 56.04 \\
& & & & & & & \\
\hline
\end{tabular}

The tables presented above, as well as more analytical tables here omitted due to lak of space, enable us to make the following observations, always remembering that these results are still preliminary and will require further verification. First of all we can see that the average claims ratio for companies offering damage insurance in Italy is around $79 \%$, with a minimum of $-50 \%$ for the company Aachener und Muenchen and a maximum of $700 \%$ for Multiassicurazione Cotoni. In the life insurance sector on the other hand the average ratio is $130 \%$, with extremes of $-195 \%$ for Italica Dival Vita and of $426 \%$ for Riunione Adriatica di Sicurtà.

The average purchasing ratio is $21 \%$ and is fairly concentrated with a minimum of $-60 \%$ for Assicurazioni Internazionali and a maximum of $175 \%$ for National Union Fire. In the life sector the average ratio is $11 \%$, though here there is a considerable spread, with a minimum of $-6800 \%$ for Italica Dival Vita and a maximum of $943 \%$ for Lavoro e Sicurtà.

Administrative expenses appear to bc less important with an average of $11 \%$, but again the spread is considerable, with a minimum $0.00 \%$ for Mutual Firc Marine \& Inland and a maximum of $1300 \%$ for Taisho Marinc and Firc. In the lifc insurance sector on the other hand the average is $36 \%$, with extremes of $-2900 \%$ for Meie Vita and $1600 \%$ for Sara Vita.

The total expenses index for the damage sector shows an avcrage of $32 \%$ but with a considerable spread and, obviously, extremes equal to those shown for the preceding index. In the life sector on the other hand the averagc is $148 \%$ with a minimum of $-7333 \%$ for Italica Dival Vita and a maximum of $2050 \%$ for Sara Vita.

The combined or trade ratio gives an average of $111 \%$ with a minimum of $-50 \%$ for Aachener und Mucnchen and a maximum of $1400 \%$ for Taisho Marine and Fire. In the life sector the average is $277 \%$ with extremes equal to those for the prcceding index. 
The ratio of charges for assets and loans to carnings derived from assets and loans showed an average, for the damages sector, of $6 \%$, but with a wide spread, the minimum being $0.00 \%$ (a number of companies returned this result since they obviously do not have carnings of this kind) and the maximum $207 \%$ for Alpi Assicurazioni. In the life sector the averagc was $11 \%$ with a maximum of $68 \%$ for Gan Vie.

The ratio of costs to carnings in the area of tcchnical management showed an average of $100 \%$, with only a very modest spead. The minimum result of $30 \%$ came from Euritass and the maximum of $118 \%$ from Gothacr Versicherung. The life scctor showed similar results, the average being $105 \%$, the minimum $80 \%$ for Assicuratrice Edile and the maximum $133 \%$ for Italica Dival Vita.

Profitability on real estate investments was, on average, $7.25 \%$. The spread was fairly small with a minimum of $0.00 \%$ for companies which do not make investments of this kind, and a maximum of $63 \%$ for Lloyd Italiano. In the life sector the indcx was decidedly better, with an average of $12 \%$ and a maximum of $24 \%$ for FATA.

The profitability of capital owned was, on average, $8 \%$, but the spread was considerable with a minimum of $-916 \%$ from $\mathrm{R}+\mathrm{V}$ Allgemeine Versicherung $\mathrm{AG}$ and a maximum of $1950 \%$ from Cigna Insurance. Again the life sector was able to show a higher level of profitability with an average of $13.5 \%$. 


\section{BIBLIOGRAPHY}

BACCARAN1, C. (1987), "Methodological aspects for assessing productivity in companys run by city councils: the case of municipal electricity and energy companies", Sinergie, CUE1M, no. 14, 1987.

BORGHES1, A. (1985). Risk Management, Economy and Organization. Theory and Practice. Cedam, Padua, 1985.

BORGHES1, A. (1988), Insurance Marketing, Cedam, Padua, 1988.

CARTER, R. L. (1979). Economics and Insurance, PH Press. Stockport, 1979.

CER1AN1, G. (1984), Critical observations on the obligatory content of some balance sheets, Luev, Verona. 1984.

FOURAST1E, J. (1959), Productivity, Garzanti, Milan, 1959.

GREGERMANN, 1. B. (1987), "Productivity Management", in FR1ARS E. M. - GOGEL R. N.. The Financial Service Handbook, Wiley \& Sons. New York, 1987.

GREENE, M. R. and SERBE1N. O. S. (1981). Risk Management: Text and Cases, Reston Publishing Co., Reston, 1981.

GREENE, M. R. and TRIESCHMANN, G. S. (1981), Risk and Insurance, South-Western Publishing Co., Cincinnati, 1981.

KENDR1CK, J. W. (1985), "Measurement of output and productivity in the service sector", in INMAN, R. P. (1985), Managing the Service Economy, Cambridge University Press, Cambridge, 1985.

LAWLOR, A. (1985), Productivity Improvement Manual, Gower, London, 1985.

PANATI. G. and GOL1NELl1, G. (1988), Industrial and Commercial Economic Technique, La Nuova Italia Scientifica, Rome, 1988.

PFEFFER, 1. and KLOCK, D. R. (1974), Perspectives on Insurance, Prentice-Hall, Englewoods Cliffs, 1974.

RATCL1FF, A. R. N. (1983), "The 1mpact of Productivity in the Insurance Cycle", Geneva Papers, no. $28,1983$.

WILliAMS, C. A. and HE1NS, R. M. (1976), Risk Management \& Insurance, McGraw Hill, New York, 1976. 